\section{Pseudo-band Structure of Liquid Metals}

Keun Su KIM and Han Woong YEOM

The splendid success of modern condensed matter physics is largely based on the band structure theory, which relies on the prefect periodicity of crystalline solids and the neglect of electron-electron interactions. This framework, however, fails to work for systems with nontrivial electronelectron interactions and those with substantial disorders in their crystalline structures. These two cases, strongly correlated electronic systems and disordered systems, remain as the most challenging unsolved issues in current condensed matter physics. In this paper, we review the recent progress in experimental studies on the electronic structures of disordered systems, especially those of liquid metals. We introduce the concept of a pseudo-band structure, named the 'radial band structure' by us, which can quantitatively explain the electron spectral functions observed for liquid metals. This framework is based on the generic properties of wave scatterings in disordered media and the well-established structural characteristics of liquids.

\section{저자약력}

김근수 박사는 2010년 연세대학교 물리학과에서 금속 단원자막의 전자구조 에 관한 광전자분광연구로 박사학위를 취득하였고, 현재는 미국 Lawrence Berkeley National Laboratory에서 박사후 연구원으로서 광전자분광, 광 전자현미경, 주사탐침현미경을 활용한 그래핀의 전자구조 연구를 수행하고 있다.

염한웅 교수는 1996년 토호쿠대학 물리학과에서 반도체표면 흡착원자층의 원자 및 전자구조에 대한 광전자분광 연구로 박사학위를 취득하였으며, 일 본 동경대 이학부에서 조수와 전임강사를 지냈고, 2000년 귀국, 2010년까 지 연세대학교 그리고 그 이후 현재까지는 포항공대 교수로 있다. 그는 반 도체표면에 형성되는 원자수준 구조체 연구에서 세계적인 선도연구자로 꼽 히고 있으며, 특히 금속원자선의 전자물성 연구분야를 개척하고 발전시켜 왔다. 2012년까지 교육과학기술부 창의연구단 원자선원자막연구단을 이끌었 고, 2012년 다시 새로운 창의연구단 저차원전자대칭성연구단을 시작하였다. 한국물리학회 학술상, 이달의 과학기술자상 등 다수의 상을 수상하였으며, Phys. Rev. Lett. 25편을 포함, 140 여 편의 논문을 저술하였다. (yeom@postech.ac.kr)
현대의 응집물질물리학은 결정구조를 가지는 고체의 주기성 에 기반하여 전자들 간의 상호작용을 무시한 밴드이론에 바탕 을 두고 눈부신 발전과 성공을 거두어 왔다. 하지만 이러한 단 순한 근사는 전자간 상호작용이 충분히 큰 경우, 그리고 결정 성이 결여되는 경우에 있어서, 그 의미를 잃게 되고, 이 두 가 지 경우들은, 강상관전자계와 무질서계로서, 현재의 응집물질 물리학이 풀어가야 할 가장 중요한 과제로 남아있다. 본 리뷰 에서는 무질서계의 전자구조, 특히 액체금속의 전자구조에 대 한 최근의 실험적 성과를 정리하고, 본인들이 제시한 액체금속 의 유사전자밴드구조 (방사형 밴드구조라 불리움) 형성에 대한 개념을 소개한다. 이 개념은 무질서계에서의 파동의 산란이 가 지는 일반적인 성질에 주목하여, 이미 잘 정립된 액체의 구조 적인 특성을 기초로 실험적으로 발견된, 액체금속의 전자들이 가지는 에너지-운동량 관계를 정량적으로 기술할 수 있다.

\section{시작하는 글}

응집물질물리에서 입자의 운동은 기본적으로 양자역학과 슈 뢰딩거방정식의 지배를 받는다. 하지만 결정고체 내부에는 아 보가드로 수에 해당하는 수많은 원자들이 존재하기 때문에 그 안을 움직이며 전하와 스핀을 지녀 서로 강하게 상호작용하는 전자들의 운동을 수학적으로 완벽하게 기술하는 것은 불가능 하다. 때문에 전자의 운동을 간단하게 기술하기 위해서 결정고 체 특유의 주기적인 성질에 의존하는 근사법을 활용하게 된다. 1929년 Bloch에 의해 제안된 밴드이론(band theory)은 바로 이러한 고체의 주기성에 기반을 두고 있으며, 고체물질의 전자 를 기술하는 기본 개념을 제공할 뿐만 아니라, 오늘날까지 전 자간의 상호작용이 비교적 약한 경우 고체 물질의 전기적, 광 학적 성질을 설명하는 데 중추적인 역할을 해 왔다.

이처럼 고체의 전자물성을 기술하는 뼈대가 되는 이론은 기본적으로 주기적인 구조에 그 기반을 두고 있지만 현실에 존재하는 물질들은 대부분 많은 수의 국소적인 또는 비국소 적인 결함들이 존재하여 주기성을 파괴하고 계의 무질서 (disorder)를 증대시킨다. 이러한 결함은 특히 복잡한 화합물 이나 저차원 물질계에서 물질의 물성을 결정하는 데 지대한 영향을 주게 되며, 따라서 무질서와 결함에 대한 연구는 현대 고체물리학의 핵심적인 주제로 연구되어 왔다. 특히, 고체물 
질 내부의 무질서도가 매우 커지는 경우에는 물질 자체가 더 이상 주기적인 구조를 갖는 결정고체의 틀에 부합하지 않는 새로운 상태를 형성하게 된다. 이러한 경우는 그 무질서도의 정 도에 따라 준결정(quasi-crystals), 비결정성 고체(amorphous solids), 유리금속(glassy metals), 액체금속(liquid metals)과 같이 광범위하게 발견되는 다양한 물질계들이다. 이러한 물질 들에는 그 구조상에 긴 범위 질서(long-range order)가 전혀 존재하지 않기 때문에, 전자 구조를 기술하는 것이 수학적으 로 매우 까다로우며, 오늘날까지 정립된 이론은 존재하지 않 는다. 사실, 질서도가 높은 결정고체는 다양하게 존재하는 응 집물질에서 작은 일부분에 불과하기 때문에, 결정구조가 상실 된 경우의 무질서한 퍼텐셜 환경에서 전자상태를 기술하고 전자의 거동을 이해하는 것은 현대의 응집물질물리학이 해결 해야 할 중요한 난제 가운데 하나라고 할 수 있다.

본 소개 글에서는 무질서한 응집물질 중에서 가장 무질서 도가 높은 액체금속의 전자구조에 초점을 맞추어 그간의 연 구의 흐름과 배경을 간략하게 소개하겠다. 특히 지난 2004년 이래로 새롭게 시도되고 있으며 본인 등이 2011년에 중요한 공 헌을 한 '각도분해광전자분광(angle-resolved photoemission spectroscopy)' 기법과 '고체 표면에 형성된 금속 단원자막의 용융 상전이'를 활용하는 실험연구를 중점적으로 소개하고, 이러한 연구를 통해 본인들이 제시한 액체금속의 유사전자밴 드구조에 대하여 설명하고자 한다.

\section{액체금속의 구조적 특징}

액체물질이라 하여도 구조적인 질서가 전혀 없는 것은 아니며, 특유의 질서를 가지고 있는 구조를 이루고 있다. 액체 물질의 구조적인 특징은 국소적인 '액체조각(liquid fragments)'의 '방 사형 상관관계(radial correlation)'로 요약할 수 있다. 액체조각 이 형성되는 까닭은 액체의 구성원자들이 서로 모여 짧은 범위 내에서 나름대로 질서정연한 구조짧은 범위 질서(short-range order)]를 가지고 있기 때문이다. 이러한 성질은 최근 전자투 과현미경의 눈부신 발전에 힘입어 실공간에서 직접적인 관측 이 가능하기에 이르렀다. 그림 1 은 유리금속 물질을 나노빔투 과전자회절(nano-beam electron diffraction) 기법을 활용하 여 측정한 실험결과를 보여준다. ${ }^{[1]}$ 전자빔의 크기를 격자 사이 의 평균거리에 가깝도록 ( $0.36 \mathrm{~nm})$ 작게 만들어 주사할 경 우, 전자빔 회절 패턴은 그림 1 에서 보는 바와 같이 액체조각 하나의 국소적 구조의 대칭성을 반영할 수 있게 된다. 하지만 전자빔의 크기를 점차 증가시켜 가며 회절 측정을 하게 되면 이러한 특정 대칭성은 점차 사라지고 단순히 둥근 형태의 회 절 패턴을 얻게 된다. 이는 액체조각들이 오직 매우 짧은 병진
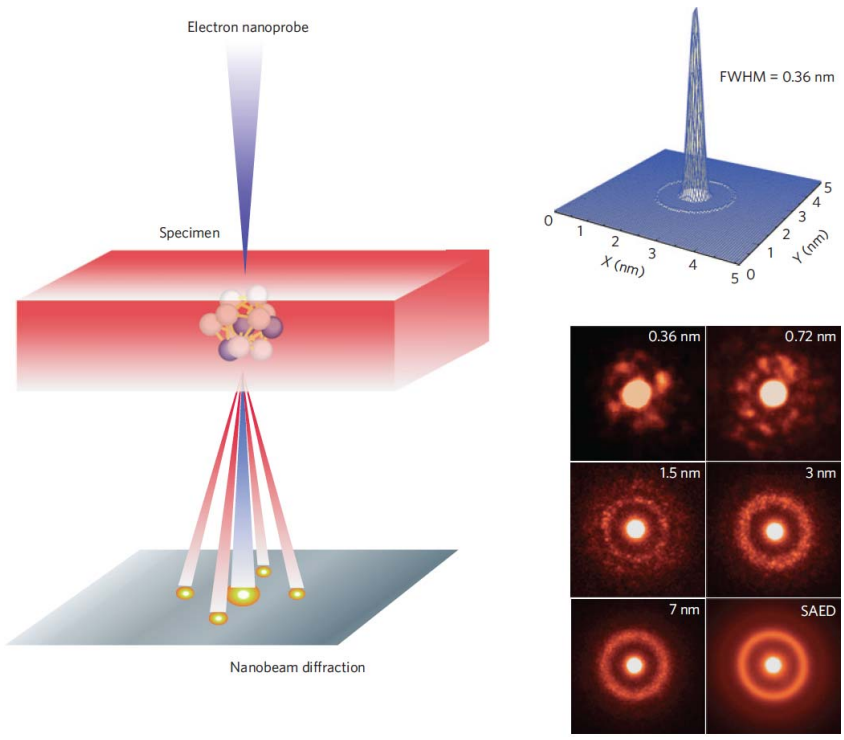

Fig. 1. Experimental scheme for nano-beam electron diffraction (left). Lower right shows nano-beam size dependence of electron diffraction patterns measured on a glassy metal. ${ }^{[1]}$

질서(translational order)와 방향질서(orientational order)만 을 갖고 서로 결맞지 않기 때문이며, 따라서 동그란 회절 패턴 은 거시적으로 방사형태의 구조적 상관관계(radial correlation)를 나타내게 된다. 방사형 상관관계란, 액체 내부의 한 임 의의 원자를 특정하였을 때, 이 원자 주변에서 방사선 방향으 로 특정한 거리에서 이웃한 원자를 발견할 확률이 높다는 것 을 가리키며, 액체 내부의 원자간의 평균적인 거리가 일정하게 유지됨을 뜻한다. 이러한 방사형 상관관계는 액체 혹은 비결정 성 고체들에서 특징적으로 나타나며, $\mathrm{x}$ 선 산란(x-ray scattering) 실험으로 관측할 수 있는 소위 '액체링(liquid ring)'이라 불리는 원통형 구조인자(structural factor)를 통해서도 쉽게 확인할 수 있다. ${ }^{[2]}$

\section{액체금속의 전자구조 연구}

앞서 설명한 바와 같이 액체금속의 중요한 구조적 특징은 일정 정도 규명이 되어 있는 반면 그 전자구조에 관한 이해는 1950 년대 이래로 다양한 이론적 근사 모델이 활발하게 제시 되어 왔으나 이를 검증하고 뒷받침할 실험적인 연구가 미진하 여 답보상태에 머무르고 있었다. 최근에 정리된 리뷰논문들에 서조차, 액체금속에서의 주기성의 상실이, 그 전자상태를 비 국소적인 자유전자에 유사한 상태로 만들 것인지, 아니면 상반

\section{REFERENCES}

[1] A. Hirata et al., Nature Materials 10, 28 (2011).

[2] H. Reichert et al., Nature 408, 839 (2000). 


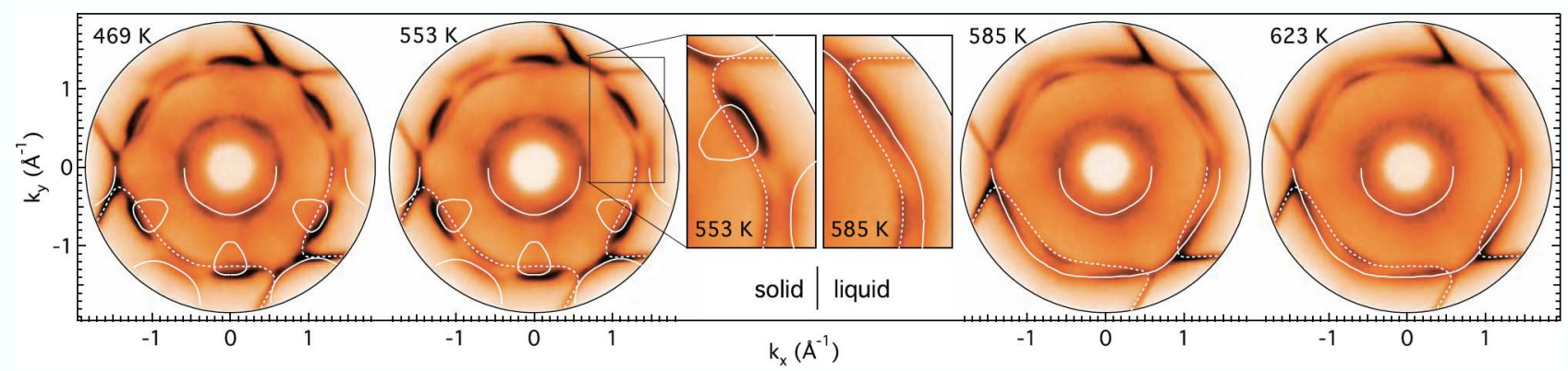

Fig. 2. Fermi surfaces of melting $\mathrm{Pb}$ monolayer on the $\mathrm{Cu}(111)$ surface measured with angle-resolved photoemission spectroscopy. The melting transition temperature is about $568 \mathrm{~K}^{[4]}$

되게, 무질서에 의하여 국소화된 전자상태를 야기할 것인지조 차 분명하게 정립되지 않고 있다. ${ }^{[3]}$ 최근까지 실험연구에서의 한계는 주로 액체금속의 용융 상전이와 이에 수반한 전자구 조의 변화를 정밀하게 연구할 수 있는 마땅한 물질과 시료준 비방법의 부재에 기인하는 바가 크다. 하지만 2000년에 Reichert 등에 의해 제시된 새로운 방법, 즉 '액체금속을 결정 고체의 표면에 형성시키는 트릭'을 이용하면 액체금속을 구성 하는 액체조각들을 액체금속의 표면에서 발생하는 약한 퍼텐 셜의 영향에 의해 일정 정도의 방향질서를 갖고 정렬하도록 만들 수 있게 된다. ${ }^{[2]}$ 이러한 방법을 활용하면 액체금속 내부 의 액체조각 고유의 대칭성이 일정 정도 유지되면서도 이들의 정렬을 통해 운동량의 방향 정보가 보존되므로, 매우 짧은 병 진질서를 갖는 물질계에 대하여서도 운동량에 의존하는 다양 한 회절적인 그리고 분광학적인 연구를 시도할 수 있게 된다.

이러한 새로운 방법론에 기반하여 2004년 스위스의 Osterwalder 등은 구리결정 표면 위에 납 단원자막을 형성시 키고 각도분해광전자분광을 활용하여 고체상태와 액체금속 상 태의 전자밴드구조 및 페르미면(Fermi surface)을 측정하는데 성공하였다. ${ }^{[4]}$ 각도분해 광전자분광법은 기본적으로 광전효과 와 전자에너지-운동량분석기를 이용하여 고체의 전자 구조를 사진을 찍듯 측정할 수 있는 실험방법이다. 이 방법은 1990년 대 이후로 고체의 전자밴드구조를 실험적으로 결정하는데 널리 활용되어 왔으나, 액체금속에까지 그 활용 범위가 확장된 것은 이때가 처음이었다. 이 연구에서는 놀랍게도 단원자막이 액화 되어도 언뜻 보아 고체상태의 밴드구조와 유사해 보이는, 특정 한 운동량에 전자상태가 집중되어 있는, 유사전자밴드구조가 관측된다는 것을 밝혔다. 측정된 액체금속의 유사밴드구조는 매우 독특한 서로 다른 두 개의 밴드로 구성되는데, 그림 2 오 른쪽에 보는 바와 같이 하나는 큰 운동량을 가지는 전자 밴드 이고 다른 하나는 안쪽의 상대적으로 운동량이 작은 홀 밴드이 다 (흰색 실선들). 바깥쪽 전자 밴드의 경우는 자유전자와 유사 한 밴드분산을 보이는데, 이는 액체상태에서 주기적인 퍼텐셜 이 사라져서 금속전자가 자유전자화되는 현상으로 비교적 쉽 게 이해할 수 있다고 본인들은 생각하고 있다. 이러한 자유전자
적인 밴드의 형성은 액체금속의 전자구조 이론들의 기본 개념 중의 하나이며, 이미 준결정계에서 실험적으로 관측된 바가 있 다. ${ }^{[5]}$ 하지만 안쪽에 나타나는 작은 홀밴드의 존재는 간단하게 설명될 수 없었는데, 아래에서 기술하듯이, 본인들의 연구는 이 러한 홀밴드야말로 액체금속 특유의 전자상태를 반영하는 것 으로 제안하고 있다. 이와 더불어, 발견된 두 유사전자밴드의 전자 결맞음길이(coherence length)도 전자스펙트럼의 넓이로 부터 측정되었는데, 이 길이는 $3 \sim 8 \AA$ 정도로 원자들의 평균 간격 수준에 가깝도록 짧아진 특징을 보여주고 있다. 즉, 액체 금속이라 하여 전자밴드가 존재하지 않는 것이 아니라, 전자상 태의 결맞음길이는 매우 짧지만 잘 정의된 유사전자밴드(일정 한 에너지-운동량 상관관계)가 존재한다는 것이다. 좀 더 자세 히 들여다보면, 전자 결맞음길이에서도 전자와 홀밴드 사이에 차이점이 존재하는데, 홀밴드가 바깥쪽 전자밴드에 비해 두 배 가량 짧게 나타난다. 이는 두 밴드가 서로 다른 물리적인 기원 을 가짐을 시사하고 있다. 이와 같이 이 연구는 액체금속이 의 외로 잘 정의된 전자밴드(전자의 에너지-운동량 상관관계라는 넓은 의미에서)를 가진다는 점을 최초로 관측하였다는 데에 그 의의가 있으나, 발견된 두 개의 밴드의 물리적인 기원과 그 두 밴드의 차이점의 원인을 규명하지 못하였다는 한계를 갖는다.

\section{액체금속의 방사형 전자구조}

앞서 언급한 Reichert 등과 Ostewalder 등의 연구는 공통적 으로 납 원자막을 활용하였는데, 이는 납이 쉽게 금속성을 띠 면서도 상대적으로 낮은 용융 상전이 온도를 가지고 있어 실험 적으로 용융전이 실험에 특히 유리하기 때문이다. 그러나 구리 결정 표면 위에 형성된 납원자막의 용융전이 온도는 약 $570 \mathrm{~K}$ 정도로 납의 벌크 결정보다는 낮은 편이지만, 실험적인 관점에 서 여전히 열적인 요동이 심해 정밀한 측정을 하기 어렵다는

\section{REFERENCES}

[3] N. C. Halder, Phys. Status Solidi B 111, 221 (1982).

[4] F. Baumberger et al., Science 306, 2221 (2004).

[5] E. Rotenberg et al., Nature 406, 602 (2000). 
단점이 있다. ${ }^{[4]}$ 즉 분광학 실험의 관점에서는 더 낮은 용융전이 온도를 가지는 계가 필요하였다. 이에, 본인들은 최근에 새롭 게 보고된, 실리콘 기판 위에 형성된 납 단원자막에 주목하였 는데, 이 경우, 납 원자의 독특한 확산 메커니즘으로 인하여 용 융 상전이 온도가 약 $280 \mathrm{~K}$ 정도까지 내려가, 보다 정밀한 분 광연구가 가능할 수 있다. ${ }^{[6]}$ 또한 구리 기판과는 달리 실리콘 기판은 그 자체가 반도체이므로 페르미 준위 부근에 기판의 전 자상태는 전혀 존재하지 않기 때문에 납 원자막 고유의 페르미 면의 변화만을 자세하게 관측할 수 있다는 실험적 이점이 있 다. 이러한 아이디어에 착안하여, 본인들은 실리콘 기판 위에 납 단원자막을 형성시키고, 그 온도를 정밀하게 조절하여 고체 에서 액체에 이르는 용융상전이 전 과정에 걸쳐 고분해능으로 전자밴드구조의 변화를 측정하였다. ${ }^{[7]}$ 아래에 기술하는 바와 같이, 본인들은 이러한 자세한 측정의 결과를 1960 년대에 제 시된 오래된 개념을 활용하여 설명하는 것에 성공함으로서 액 체의 전자구조를 이해하는 틀을 정립하게 되었다.

그림 3은 실리콘 기판 위에 형성된 납원자막의 온도에 따 른 페르미면의 변화를 각도분해 광전자분광으로 자세히 측정 한 결과이다. $280 \mathrm{~K}$ 이하의 결정상태에서는 매우 복잡한 페 르미면의 구조가 용융상전이를 거치면서 바깥쪽의 큰 전자 밴드에 기인한 전자주머니 페르미면과 안쪽의 작은 홀밴드 에 기인한 홀주머니 페르미면으로 단순화되는 것이 분명히 관찰된다. 이는 구리 기판 위의 납 원자막의 전자구조와 매우 흡사하며, 액체 상태의 납 원자막은 그 기판에 상관없이 고유 의 두 개의 원형에 가까운 페르미면들을 (즉 전자밴드와 홀밴 드를) 갖는다는 것을 보여준다. 이 실험에서 더욱 흥미로운 점은 작은 홀밴드의 페르미면이 상전이 직후인 $300 \mathrm{~K}$ 근방 에서는 원형에 가까운 모습을 보이다가 온도를 증가시킴에 따라 점차 육각 형태로 변화한다는 것이다. 그 결과 바깥쪽 전자밴드와 안쪽 홀밴드는 모두 모서리가 둥근 육각 형태를 띠고 그 꼭짓점이 서로 30 도 돌아간 독특한 대칭성을 보이게 된다.

이러한 두 개의 페르미면의 존재, 액체상태에서의 페르미면 의 독특한 대칭성, 그리고 온도에 따른 밴드의 형태 변화는 Bloch 이론에서 예측되는 주기적인 밴드구조의 범위 내에서 이해할 수 없는 것으로, 액체금속 특유의 구조적 특징을 고려 해야만 설명이 가능하다. 그림 3 아래에는 액체금속의 전자구 조를 예측하기 위해 1960 년대 영국의 이론가들에 의해 제시 된 다결정근사 모델과 이상적인 액체 모델의 페르미면을 각각 나타낸다. ${ }^{[8]}$ 이 모델은 자유전자들이 액체금속의 스크린된 이 온퍼텐셜에 의한 산란효과를 고려하는 근사법을 사용하였는 데, 여기에서 액체 내 전자의 산란은 원자핵의 평균질서거리와 전자의 평균자유거리간의 상관관계에 의존한다. 평균질서거리

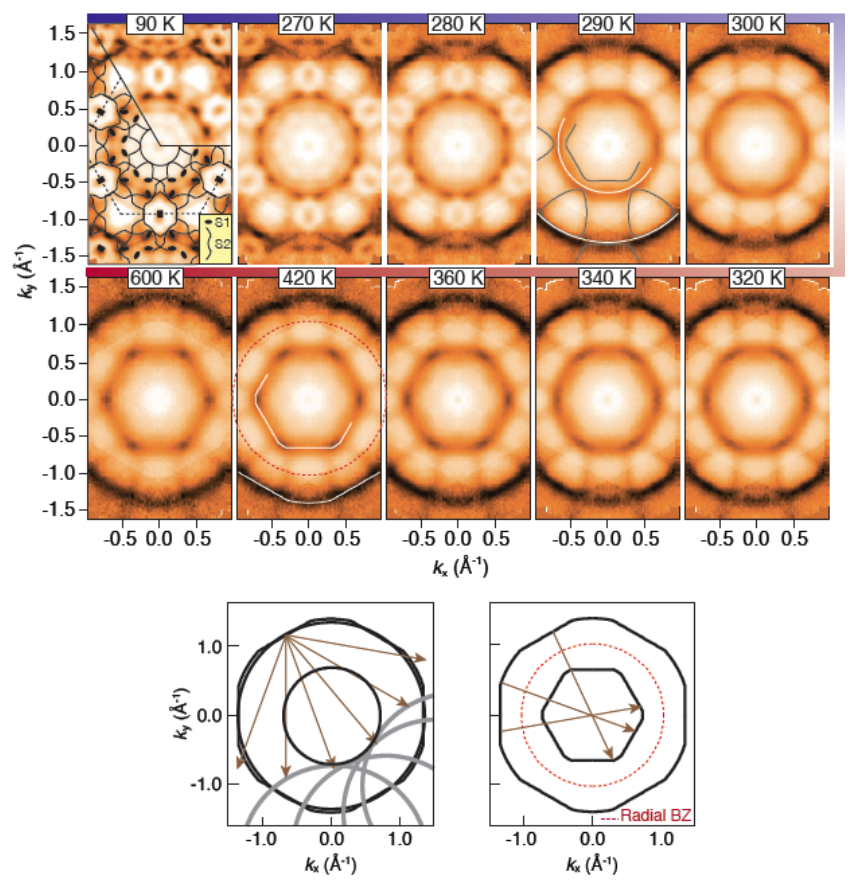

Fig. 3. Evolution of the Fermi surface with temperature during the melting transition of $\mathrm{Pb}$ monolayer on the $\mathrm{Si}(111)$ surface. Bottom shows schematic illustrations of two possible scattering mechanisms in a liquid metal (left: polycrystalline model, right: ideal liquid model). ${ }^{[7]}$

가 평균자유거리보다 큰 경우 다결정(poly-crystals) 혹은 유 리금속 상태의 경우와 흡사하여 국소적으로는 Bloch 상태에 가깝게 된다. 이 경우 액체금속의 구성원자의 평균 거리로 그 크기가 결정되는 산란벡터에 따라 방위각에 대해 균일하게 산 란이 일어나고, 바깥쪽 자유전자 밴드를 모든 방향에 대해 균 일하게 병진 이동시키게 된다. 이렇게 병진된 전자밴드들은 서로 중첩되어 안쪽에 둥근 형태의 작은 홀밴드를 형성하는 것이다(그림 3). 반면 계의 무질서도가 증가하여 원자핵의 평 균질서거리가 전자의 평균자유거리와 유사한 수준으로 작아지 는 경우를 이상액체 모델로 설명하는데, 이 경우 전자의 산란 특성은 앞서 언급한 원자들 사이의 방사형 상관관계가 주는 이온 퍼텐셜의 지배를 받게 된다. 이 경우는 특히 방사선방향 으로 우세한 산란(radial scattering)이 발생하게 된다. 이러한 방사선방향의 산란은 무질서도가 높은 계에서의 모든 파동의 산란에 적용되는 매우 일반적인 현상으로서, 예를 들면 우유와 같은 무질서한 콜로이드 물질에서는 빛의 후방산란이 우세하 여 탁한 빛깔을 띠게 되는 것과 유사한 원리이다. 또한, 이 원

\section{REFERENCES}

[6] S. C. Jung and M. H. Kang, Phys. Rev. B 84, 155422 (2011).

[7] K. S. Kim and H. W. Yeom, Phys. Rev. Lett. 107, 136402 (2011).

[8] S. F. Edwards, Proc. R. Soc. A 267, 518 (1962). 


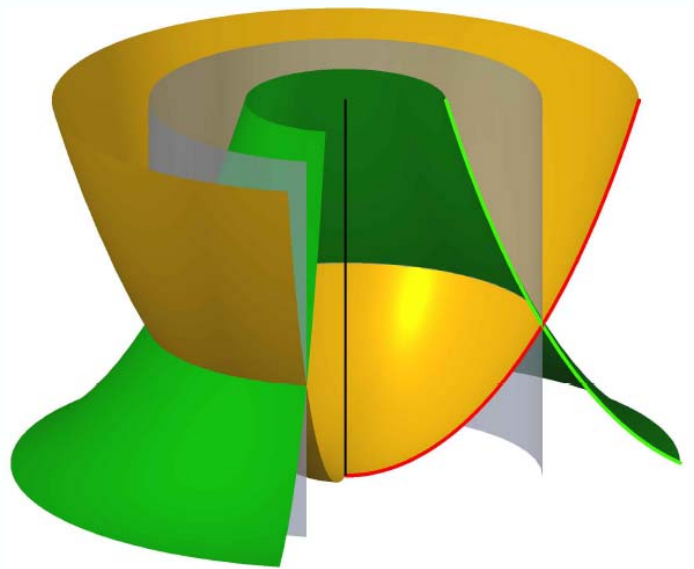

Fig. 4. Illustration of the radial band structure, a unique characteristic of liquid metals. The yellow is an outer free-electron-like band and the green is a folded hold band. The gray cylinder represents the radial Brillouin zone.

리는 무질서계가 존재하는 전자계에서 특징적으로 나타나는 약한 앤더슨 국소화 현상과 일맥상통한다.

실제로 액체금속은 온도가 증가함에 따라 열적 동요에 의하 여 계의 무질서도가 점차 증가하므로, 전자의 산란 특성은 균 일한 산란으로부터 방사형 산란이 우세한 형태로 전이하게 되 는 것이다. 이러한 이론적 모델의 예측은 앞서 언급한 주요 실 험 결과들을 잘 설명한다. 즉 일단 무질서한 상태가 되어 결정 성을 상실하면, 전자들은 자유전자와 유사한 전자밴드를 구성 하게 되며 (바깥쪽 전자 페르미면), 내부의 원자들이 주는 이 온퍼텐셜에 의한 전자산란에 의해 전자밴드 안쪽에 홀밴드(안 쪽의 홀 페르미면)가 만들어진다. 나아가, 작은 홀 페르미면의 온도에 따른 형태 변화도 잘 설명되는데, 다시 말해, 홀밴드의 온도에 따른 형태 변화(원형에서 육각형으로)는 상전이 직후 중간적인 유리상태를 (균일한 전자산란) 거쳐 더욱 무질서한 액상으로 (방사산란이 우세) 전이하는 점진적인 구조 전이를 반영하는 것으로 생각할 수 있다. 이때 애초의 전자밴드가 육 각형에 가까운 형태를 보이는 것은 잘 정렬된 기판의 퍼텐셜 에 의해 일정정도의 방향성을 갖게 된 액체조각들의 대칭성을 반영하는 것으로 설명할 수 있다. 또한 안쪽에 나타나는 홀밴 드에서 스펙트럼 넓이가 더 크게 나타나는 현상도 이 홀밴드 가 바깥쪽 전자밴드의 복잡한 산란과 중첩에 의해 만들어짐을 고려하면 자연스럽게, 그리고 정량적으로, 설명할 수 있다.

위와 같은 액체금속의 전자구조의 특징을 좀 더 직관적으로 설명하기 위해서는, 결정고체의 주기적인 브릴루앙 영역과 준결 정의 준브릴루앙 영역에 대응하는, ${ }^{[5]}$ 액체의 방사형 브릴루앙 영 역이라는 개념을 도입하면 편리하다. 실험적으로 관측된 바깥쪽 전자밴드와 안쪽 홀밴드의 중점을 연결하여 밴드가 대칭적으로 접히는 운동량 지점을 연결해 볼 경우 그림 3 의 붉은색 점선과 같이 동그란 형태를 보이게 된다. 따라서 액체금속의 전자구조

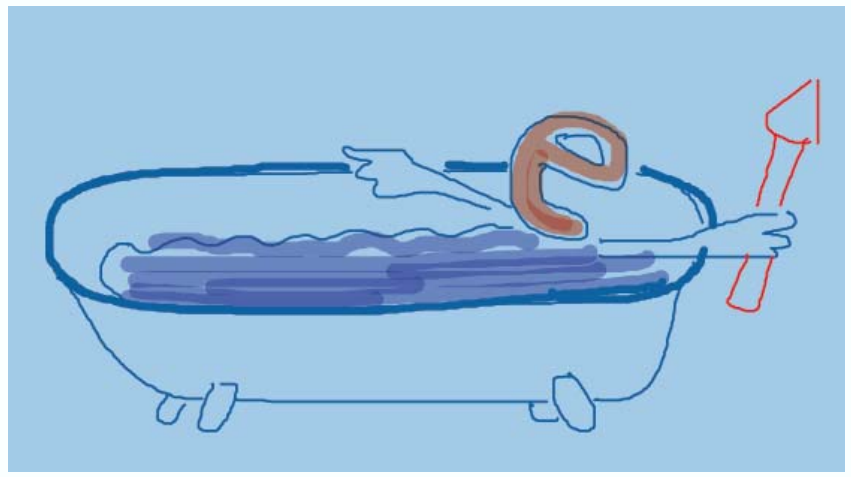

Fig. 5. Relaxed electrons in liquids? (Cartoon by H. W. Yeom)

는 그림 4와 같이 바깥쪽 전자밴드가 동그란 형태의 기준점(회색 원통)을 중심으로 반대로 접힌 이중의 밴드구조를 갖게 되는데, 이러한 기준점의 운동량 크기는 액체 상태의 평균 원자거리의 역 수에 비례한다. 이와 같이 독특한 방사형 브릴루앙 영역은 일반 적인 이차원 고체물질이 갖는 다각형 브릴루앙 영역과 대조되며, 이러한 특징들을 통칭하여 본인들은 방사형 전자구조(radial band structure)라는 명칭을 정의하였다. 이는 무질서한 계에서의 방사형 전자산란과 함께 액체 내부의 전자의 거동을 이해하는 데 있어 핵심적인 개념에 해당하며, 액체금속의 구조적 특징인 방사 형 상관관계에 기인하는 전자구조 상의 특이성이라 할 수 있다.

\section{맺는 글}

지금까지 액체금속 물질의 정립된 구조적 특징과 그에 따른 전자구조에 관한 최근의 핵심적인 실험연구결과를 소개하였다. 액체 물질은 인간의 삶 속에서 친숙하게 발견할 수 있는 물질 상태이며 그 잠재적인 활용성은 무궁무진하다고 할 수 있다. 하지만 그 내재적인 복잡성으로 인하여 물리적인 성질의 이해 는 상당 부분 아직 미개척 상태로 남아있다. 하지만 최근 들어 결정고체계 연구를 주도해 온 몇 가지 중요한 실험 방법들이 하나 둘씩 액체 물질의 연구에도 응용되기 시작하면서, 그 기본 적인 구조와 전자구조를 이해하는 토대가 마련되어 가고 있는 상황이다. 이는, 구조적인 면에서는, 다양한 회절 실험들이 제 시한 액체조각들의 짧은 거리 질서와 방사형 상관관계이며, 전 자구조의 면에서는, 본인들이 밝힌, 방사형 전자밴드구조가 되 겠다. 이는 궁극적으로 액체 속을 전파하는 입자의 거동을 일반 적으로 기술하는 이론 모델을 향한 발걸음들이라 할 수 있겠다. 지난 반세기 동안 고체 물질에 대한 심도 깊은 연구가 고온초 전도 현상이나 양자홀 효과와 같은 놀라운 물리 현상을 보여주 었듯, 미개척의 영역인 액체 물질에 대한 연구로도 그와는 또 다른 흥미롭고 놀라운 현상이 발견되고 이러한 발견이 인류에 게 유익한 위대한 발명으로 이어지기를 기대해 본다. 